\title{
Nano-Bioceramic Synthesis from Tropical Sea Snail Shells (Tiger Cowrie - Cypraea Tigris) with Simple Chemical Treatment
}

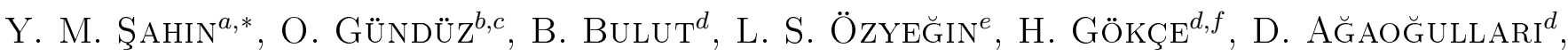

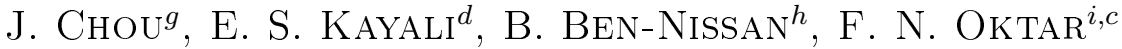

${ }^{a}$ Department of Biomedical Engineering, Faculty of Engineering and Architecture, Istanbul Arel University, Istanbul, Turkey

${ }^{b}$ Department of Metallurgy and Materials Engineering, Faculty of Technology, Marmara University, Istanbul, Turkey ${ }^{c}$ Applied and Research Centre for Nanotechnology and Biomaterials, Marmara University, Istanbul, Turkey

${ }^{d}$ Metallurgical and Materials Engineering Department, Istanbul Technical University, Istanbul, Turkey ${ }^{e}$ Bayramoglu, Kocaeli , Turkey

${ }^{f}$ Prof. Dr. Adnan Tekin Materials Scienci and Production Technology Applied Research Center, Istanbul Technical University, Istanbul, Turkey

${ }^{g}$ Research Institute of Pharmaceutical Sciences, Musashino University, Tokyo, Japan

${ }^{h}$ Department of Chemistry and Forensic Sciences, The University of Technology, Sydney, Australia

${ }^{i}$ Bioengineering Department, Faculty of Engineering Marmara University, Istanbul, Turkey

In this study several bioceramic materials (i.e. hydroxyapatite, whitlockite) were prepared by using chemical synthesis method from sea snail shells (Tiger Cowrie - Cypraea Tigris), originated from Pacific Ocean. Marine shells usually present aragonite-calcite structures and generally, complicated and pressurized equipment is necessary to convert these structures into bioceramics. Instead of using complicated systems, a basic ultrasonic equipment and simple chemical synthesis method was used in the process. DTA analysis was performed to calculate the required amount of $\mathrm{H}_{3} \mathrm{PO}_{4}$ solution in order to set the appropriate stoichiometric ratio of $\mathrm{Ca} / \mathrm{P}$ equal to 1.667 for HA bioceramic or to 1.5 for $\beta$-TCP bioceramic in the titration. The prepared batches were sintered at $800{ }^{\circ} \mathrm{C}$ and $400{ }^{\circ} \mathrm{C}$ for hydroxyapatite (HA) and $\beta$-tri calcium phosphate $(\beta$-TCP) forms respectively. X-ray diffraction analysis, scanning electron microscopy (SEM) and infrared observations (FTIR) were implemented for both TCP and HA bioceramics. By applying the chemical synthesis with basic ultrasonic equipment, this study proposes a simple way of production for nano-HA / TCP powders from a natural marine sources.

DOI: $10.12693 /$ APhysPolA.127.1055

PACS: 81.07.-b, 87.68.+z, 28.52.Fa

\section{Introduction}

A wide variety of materials has been investigated in the quest of developing novel and effective bone graft substitutes, which can either be used to repair defects and restore the irregularities in bones [1]. Having the following chemical structure $\mathrm{Ca}_{10}\left(\mathrm{PO}_{4}\right)_{6}(\mathrm{OH})_{2}, \mathrm{HA}$, is the most commonly used bioactive material for production of a new generation of biomimetic implants, aiming an ultimate level of bioactivity and biocompatibility $[2,3]$. Biological apatites attract special interest owing to their substitutional $\mathrm{Ca}^{2+}, \mathrm{PO}_{4}^{3-}$ and $\mathrm{OH}$ sites and the presence of several trace elements in the structure [4-6]. The trace elements play an important role in the overall physiological functioning, properties and in the osseointegration process [4]. Those biological HAs are ideal materials for bone grafting, maxillofacial surgery

* corresponding author; e-mail: ymugesahin@arel.edu.tr and augmentation and as bone fracture healing material in orthopedics [7]. Although, the autogenous type bone grafts are primarily chosen as golden standards for bone grafting, there are still limitations of finding a healthy donor and the possibility of requirement of additional post-surgeries [8]. Allografts, are the implants taken from a range of sources [9] and xenografts (i.e. taken from bovine bone), can also be a second choice but various potential infections may accompany these grafts [10]. Synthetic HAs, from reagent chemicals on the other hand are another possible source, but they don't include trace elements (i.e. strontium) which are essential. Currently, for this purpose, natural materials including marine structures are employed to produce calcium phosphates, with a number of synthesis methods, including high temperature calcinations [8-9] or by applying various chemical conversion processes from calcium carbonate. Corals are usually preferred as calcium carbonate sources, but these are having only calcite-aragonite based structures. Additionally various marine structures (Mussels shells [11-13], sea urchin shells [14-17] and sea snail shells [18-21]) have 
been also utilized as well. Other than marine sources, the shells of land snails [22] and egg shells of hens [23] have been the alternative sources for such bioceramics.

The production methods for these bioceramics are also very important. Usually high pressured hydrothermal methods were used for bioceramic production from cuttle fish [24], sea shells [25] and corals [26]. Chemical agitation method by a simple hot-plate stirrer [12-14, 16-19, 23] and ultrasonic equipment [12, 14-17, 20-23] enables to form TCP and HA structures by an easier way in comparison to the high pressurized hydrothermal methods [23-24].

In this study as a TCP and HA source Tiger Cowrie (Cypraea Tigris) shells were used. The Tiger Cowrie is a typical sea snail which lives in the Indo-Pacific Region. It is one of the most common sea snail (mollusk) in the Pacific Ocean and emerges in large numbers over the majority of the tropical Indo-Pacific Region (from Africa to Hawaii) [27]). The aim of this study is to produce nanobioceramic structures using a simple ultrasonic equipment and chemical synthesis method.

\section{Materials and methods}

Tiger Cowrie shells, shown in Fig. 1, were obtained from a local gift store in Istanbul-Turkey. The shells were washed and cleaned in tap water, to get rid of the possible dirt. The shells were crushed down into smaller parts and then grinded in a hand mortar. Grinded powders were sieved trough a $75 \mu \mathrm{m}$ sieve. Differential thermal analysis (DTA/TG) was conducted with a Netzsch-Gerätebau GmbH-STA (Selb/Bavaria, Germany) 449 C Jupiter Thermo-microbalance instrument, in order to determine the exact $\mathrm{CaCO}_{3}$ content of the shells (Fig. 2). The total mass loss for the shells was measured as $44.37 \%$. First the raw powders were suspended in an ultrasonic equipment and the reaction temperature was set to $80^{\circ} \mathrm{C}$. After $15 \mathrm{~min}$, the equivalent amount of $\mathrm{H}_{3} \mathrm{PO}_{4}$, with respect to the $\mathrm{CaO}$ content, was added drop by drop by titration. In this process two different $\mathrm{Ca} / \mathrm{P}$ ratios were obtained: 1.667 , corresponds the ratio of $\mathrm{HA}$, and 1.5 , for the TCP ratio. The reaction was sustained ultrasonicated for 8 hours. After evaporation, the obtained HA and TCP mixtures were placed into an incubator at $100{ }^{\circ} \mathrm{C}$ overnight for further purification. Completely dried sediments were taken for $\mathrm{X}$-ray diffraction analyses to identify the resultant crystalline phases. The SEM analysis, on the other hand, illuminates the morphology of the produced bioceramics whereas the chemical structure analyses of the powders were conducted with the FTIR spectra.

\section{Results and discussion}

SEM image, shown in Fig. 3, was taken from the fracture surface of untreated Tiger Cowrie (Cypraea Tigris) shell, which porous, layered structure can be easily seen. The SEM images of ultrasonically treated TCP and HA

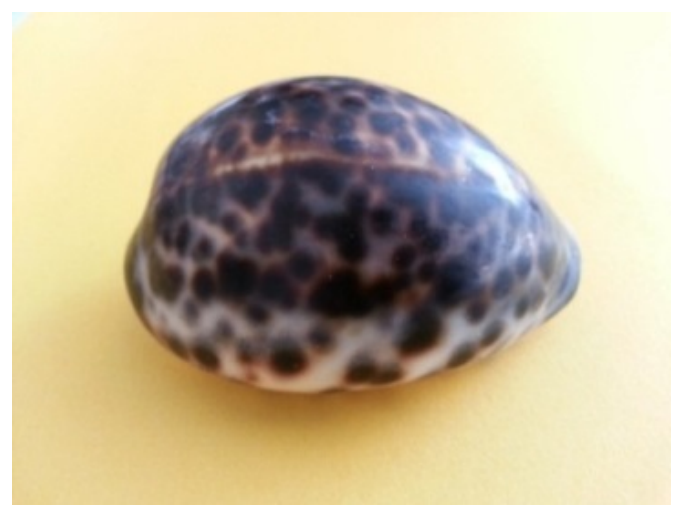

Fig. 1. Tiger Cowrie ( Cypraea Tigris).

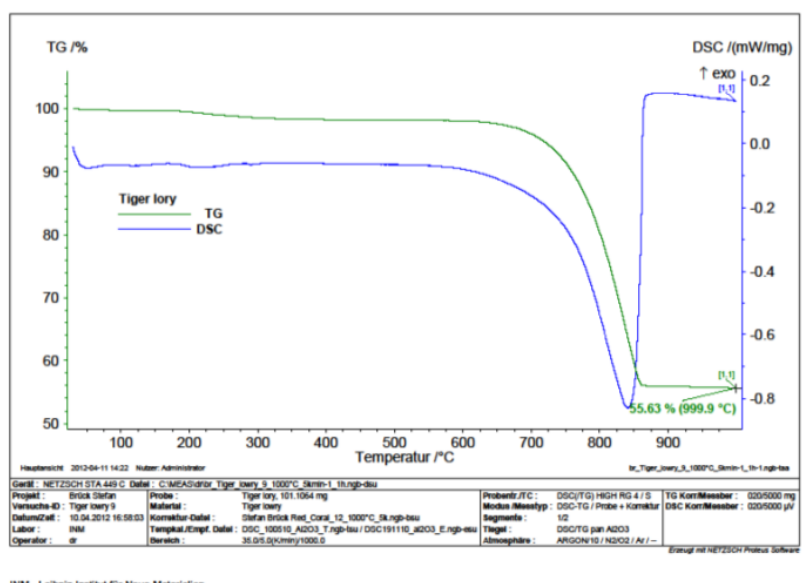

Fig. 2. DTA/TGA analysis of the Tiger Cowrie shell.

samples are given in Fig. 4 and Fig. 5 respectively. In Fig. 4 nano-structures are evident, the white arrow pointing to the right, is indicating a nano-fibriller structure of about $100 \mathrm{~nm}$ in diameter and $0.5 \mu \mathrm{m}$ in length. The white arrow pointing downwards, indicates a long fibrilar structure of $1.5 \mu \mathrm{m}$ in length and $120 \mathrm{~nm}$ in crosssection. TCP particles look like clipped fibers, these illus-

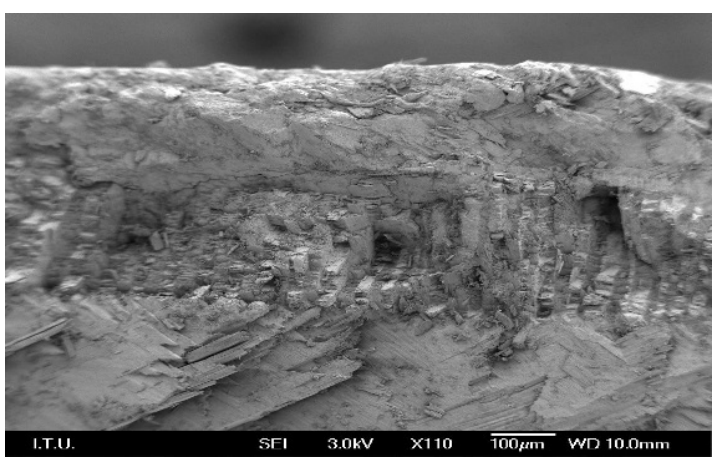

Fig. 3. SEM image from cross section of untreated Tiger Cowrie (Cypraea Tigris) shell. 


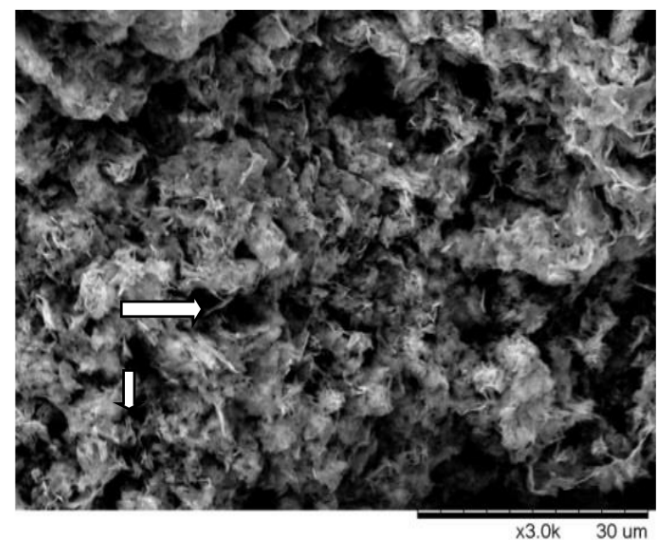

Fig. 4. SEM studies of ultrasonically treated TCP samples $(\times 3000)$ magnified.

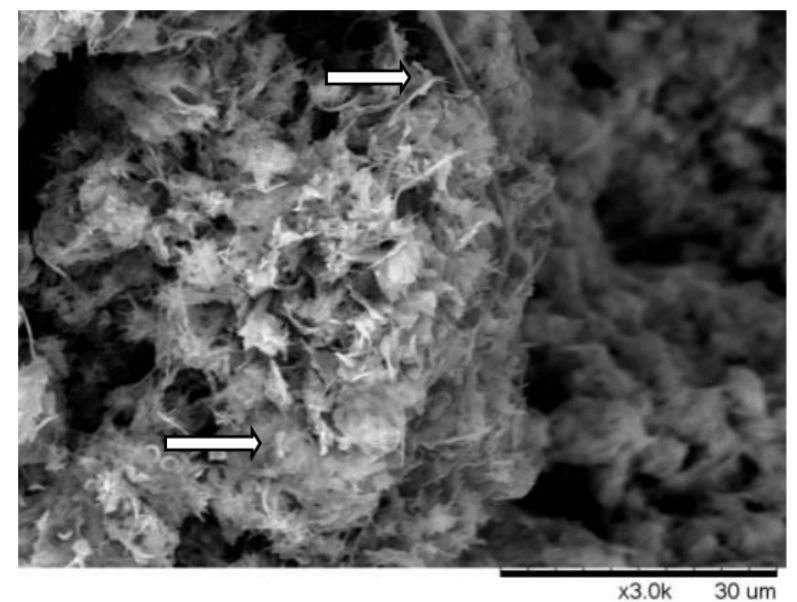

Fig. 5. SEM studies of ultrasonically treated HA samples $(\times 3000)$ magnified.

trate both small and big agglomerates. In Fig. 5 the big white arrow is indicating another nano-structured fibril with a $3 \mu \mathrm{m}$ length and a $150 \mathrm{~nm}$ diameter. The other fibrilar structures are evident through the image. The general morphology of TCP-based structures looks like a number of needles, cluttered irregularly in the image, whereas HA based structures have bigger agglomerates which clump with each other.

The x-ray diffraction data in Fig. 6 illustrate the main phases for HA and TCP bioceramics. For the HA-based materials (PDF2 card no: 04-9808), there are also some dominant whitlockite phase which can be described as $\beta$-TCP in the literature [28] (PDF2 card no: 00-2071) and some minor calcite phases are observed. For the TCP based materials on the other hand, some dominant HA and tricalcium bis phosphate (V) hydroxide phases (PDF2 card no: 07-9408) as well as calcite phases can be observed.

Figure 7 shows that the characteristic absorption peaks of HA and TCP powders were revealed by FTIR analy-

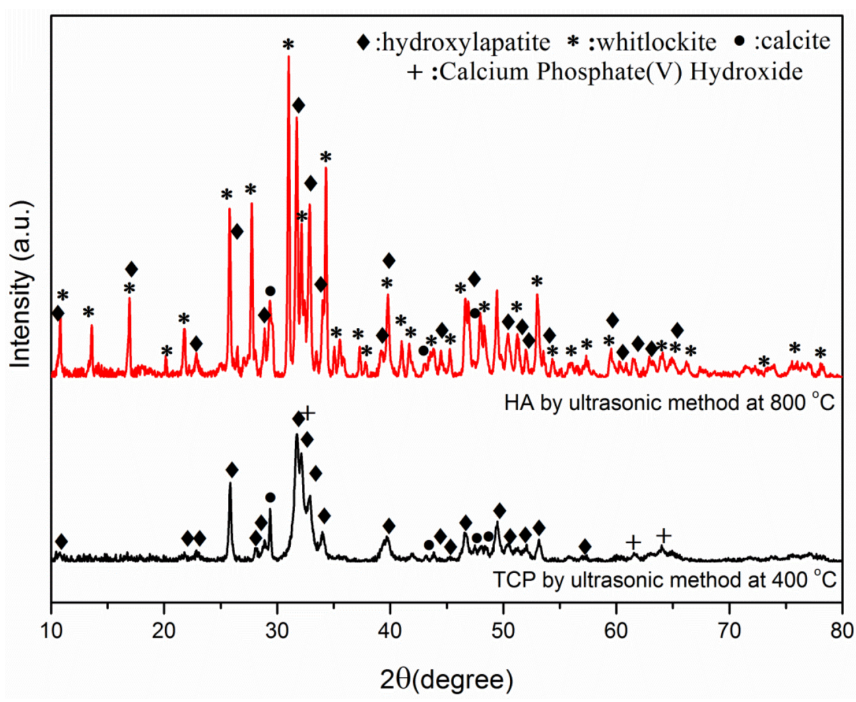

Fig. 6. X-ray diffraction patterns of ultrasonically treated TCP (lower) and HA (upper) samples.

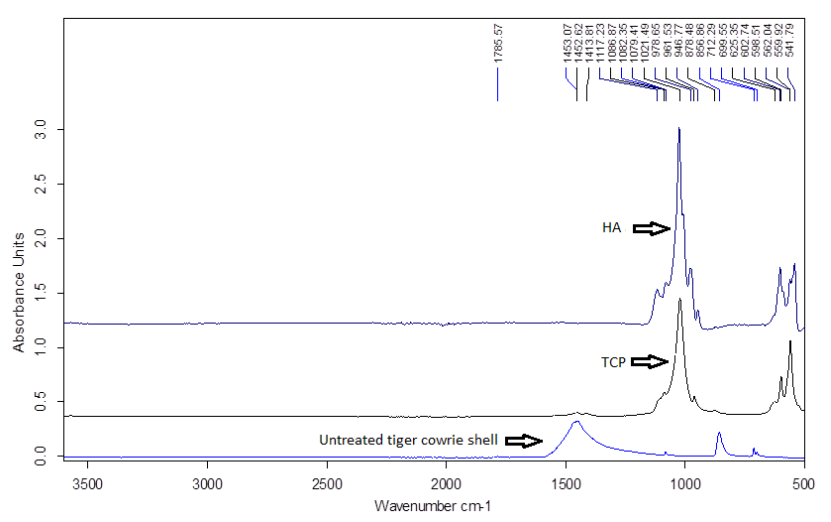

Fig. 7. FTIR patterns of ultrasonically treated and untreated (the lowest) samples.

ses. The bands at 562,599 and $625 \mathrm{~cm}^{-1}$ indicated the characteristic reflections of the $\mathrm{v}_{4} \mathrm{PO}_{4}^{3-}$ vibrations, the bands at 962 and $1022 \mathrm{~cm}^{-1}$ exhibited the $\mathrm{v}_{1} \mathrm{PO}_{4}^{3-}$ vibrations and the band at $1087 \mathrm{~cm}^{-1}$ was due the $\mathrm{v}_{3} \mathrm{PO}_{4}^{3-}$ vibrations, which correspond to the asymmetric bending vibrations, symmetric stretching and asymmetric stretching of phosphate groups respectively. As the calcination temperature increased from $400^{\circ} \mathrm{C}$ to $800^{\circ} \mathrm{C}$, the peaks of the phosphate group became more apparent at 625 , 962 and $1087 \mathrm{~cm}^{-1}$. There are no peaks assigned to the $\mathrm{O}-\mathrm{H}$ stretching vibrations in Fig. 7. In the FTIR spectra carbonate groups $\mathrm{CO}_{3}^{2-}$, generally identified by absorption band at $1457 \mathrm{~cm}^{-1}\left(\mathrm{v}_{3} \mathrm{CO}_{3}^{2-}\right)$, and especially by the presence of the band at $870 \mathrm{~cm}^{-1}$, have been used for estimation of carbonates $\left(\mathrm{v}_{3} \mathrm{CO}_{3}^{2-}\right)$ in phosphates. The absence of these bands illustrated the success of the process. 


\section{Conclusions}

In this study a simple mechano-chemical method was used to obtain nano-bioceramics. When compared to previous studies, which have used complicated and time consuming methods, this study presents an advantage by only using ultrasonic equipment in the production of nano-bioceramics. Thus, the production of nano sized HA and TCP particles from Tiger Cowrie shells is possible and these can be considered as good candidates for new generation of biological implants.

\section{References}

[1] F.N. Oktar, P. Valerio, G. Goller, S. Agathopoulos, A.M. Goes, M.F. Leite, Key Engineer. Mater. 309, 449 (2006).

[2] H. Gökçe, D. Ağaoğulları, M. Yetmez, O. Gündüz, C. Aktaş, M.L. Öveçoğlu, I. Duman, S. Agathopoulos, F.N. Oktar, J. Biomech. 44, 7 (2011).

[3] L. Duta, N. Serban, F.N. Oktar, I.N. Mihailescu, Optoelectr. Advance. Mater.-Rap. Com. 7, 1040 (2013).

[4] S. Salman, O. Gunduz, S. Yilmaz, M.L. Öveçoğlu, R.L. Snyder, S. Agathopoulos, F.N. Oktar, Ceram. Int. 35, 2965 (2009).

[5] O. Gunduz, E.M. Erkan, S. Daglilar, S. Salman, S. Agathopoulos, F.N. Oktar, J. Mater. Sci. 43, 2536 (2008).

[6] F.N. Oktar, M. Yetmez, S. Agathopoulos S, T.M. Lopez Goerne, G. Goller, I. Ipeker, J.M.F. Ferreira, J. Mater. Sci-Mater. Med. 17, 1161 (2006).

[7] Z.E. Erkmen, Y. Genc, F.N. Oktar, J. Am. Ceram. Soc. 90, 2885 (2007).

[8] L.S. Ozyegin, F.N. Oktar, G. Goller, E.S. Kayali, T. Yazici, Mater. Lett. 58, 2605 (2004).

[9] G. Goller, F.N. Oktar, S. Agathopoulos, D.U. Tulyaganov, J.M.F. Ferreira, E.S. Kayali, I. Ipeker, J. Sol-Gel Sci. Tech. 37, 111 (2006).

[10] S.V. Dorozhkin, J. Mater. Sci. 44, 2343 (2009).

[11] U. Tüyel, E.T. Öner, S. Özyeğin, F.N. Oktar, J. Biotechnol. 131, S65 (2007).

[12] I.J. Macha, L.S. Ozyegin, J. Chou, R. Samur, F.N. Oktar, B. Ben-Nissan, J. Australia. Ceram. Soc. 49, 122 (2013).

[13] F.N. Oktar, U.Tuyel, N. Demirkol, O. Gunduz, R. Samur, S. Kannan, S. Agathopoulos, Int. J. Artif. Organs 33, 467 (2010).

[14] M.L. Tamasan, L.S. Ozyegin, F.N. Oktar, V. Simon, Mater. Sci. Engineer. C 33, 2569 (2013).

[15] R. Samur, L.S. Ozyegin, D. Agaogullari, F.N. Oktar, S. Agathopoulos, C. Kalkandelen, I. Duman, B. Ben Nissan, Metalurg. 52, 375 (2013).

[16] D. Agaogulları, D. Kel, H. Gokce, I Duman, M.L. Öveçoğlu, A.T. Akarsubasi, D. Bilgic, F.N. Oktar, Acta Phys. Pol. A 121, 23 (2012).

[17] D. Kel, U. Karaçaylı, M. Yetmez, H. Gökçe, D. Ağaoğullari, M.L. Öveçoğlu, I. Duman, E.S. Kayalı, F.N. Oktar, Int. J. Artif. Organs 34, 700 (2011).

[18] O. Gunduz, Y.M. Sahin, S. Agathopoulos, B. BenNissan, F.N. Oktar , J. Nanomater. 2014, 1 (2014).
[19] O. Gunduz, Y.M. Sahin, S. Agathopoulos, D. Ağaoğulları, H. Gökçe, E.S. Kayali, C. Aktas, B. Ben-Nissan, F.N. Oktar, Key Engineer. Mater. 587, 80 (2014).

[20] F.N. Oktar, S. Agathopoulos, L.S. Ozyegin, I.G. Turner, O. Gunduz, N. Demirkol, S. Brück, B. Ben-Nissan, R. Samur, E.S. Kayali, C. Aktas, Key Engineer. Mater. 529, 609 (2013).

[21] L.S. Ozyegin, F. Sima, C. Ristoscu, I.A.Kiyici, I.N. Mihailescu, O. Meydanoglu, S. Agathopoulos, F.N. Oktar, Key Engineer. Mater. 493, 781 (2012).

[22] D. Kel, H. Gökçe, D. Bilgiç, D. Ağaoğulları, I. Duman, M.L. Öveçoğlu, E.S. Kayalı, I.A. Kiyici, S. Agathopoulos, F.N. Oktar, Key Engineer. Mater. 493, 287 (2012).

[23] K.P. Sanosh, M.C. Chu, A. Balakrishnan, T.N. Kim, S.J. Cho, Mater. Lett. 63, 2100 (2009).

[24] J.H.G. Rocha, A.F. Lemos, S. Agathopoulos, P. Valério, S. Kannan, F.N. Oktar, J.M.F. Ferreira, Bone 37, 850 (2005).

[25] A.F. Lemos, J.H.G. Rocha, S.S.F. Quaresma, S. Kannan, F.N. Oktar, S. Agathopoulos, J.M.F. Ferreira, J. Euro. Soc. 26, 3639 (2006).

[26] B. Ben Nissan, A. Milev, R. Vago, Biomater. 25, 4971 (2004).

[27] http://www.aquaticcommunity.com/SwSnails/ TigerCowrie.php.

[28] J.J. Song, M.S. thesis, An in vitro investigation of the spatial control involved in collagen mineralization, University of Toronto, 2010. 